\title{
EL DESARROLLO JURISPRUDENCIAL DEL DERECHO A LA VIVIENDA EN BOLIVIA. UNA RUPTURA JURÍDICA EN CIERNES*
}

\author{
THE JURISPRUDENCE DEVELOPMENT \\ OF BOLIVIA'S RIGHT TO HOUSING. \\ A LOOMING LEGAL RUPTURE
LE DÉVELOPPEMENT DE LA JURISPRUDENCE SUR LE DROIT AU LOGEMENT DE LA BOLIVIE. UNE RUPTURE JURIDIQUE IMMINENTE

Fernando CASADO GUTIÉRREZ**

\begin{abstract}
RESUMEN: El trabajo que se presenta a continuación hace un recorrido normativo y jurisprudencial en materia del derecho a la vivienda de lo ocurrido en el Estado Plurinacional de Bolivia desde la entrada en vigor de la Constitución Plurinacional del Estado de 2009 y el Tribunal Constitucional Plurinacional (TCP).

La investigación aspira a evaluar si los cambios normativos incluidos en la Constitución, considerados como contrapuestos con la visión liberal y que valoran como justiciable el derecho a la vivienda, han tenido una correlación en la práctica con la impartición de justicia a la altura de la carta magna. Para ello realizaremos un análisis de la jurisprudencia en el plano cuantitativo, del número total de decisiones emitidas por el TCP, y cualitativo al profundizar en las argumentaciones de las sentencias consideradas como emblemáticas en materia de protección y garantía del derecho a la vivienda. ${ }^{1} \mathrm{El}$ trabajo irá acompañado de entrevistas,
\end{abstract}

* Recibido el 13 de marzo de 2020 y aceptado para su publicación el 15 de marzo de 2021.

* Investigador en la Universidad Técnica de Manabi. Licenciado en derecho por la Facultad de Granada (España), maestría en derechos humanos y democratización en la European Inter-University en el año 2004 en Venecia (Italia), doctorado en comunicación social en el año 2012 en la Facultad de Comunicación de la Universidad de La Laguna (España).

1 Las sentencias serán mencionadas de acuerdo con su número y año de emisión, por ejemplo: 0426/2013. 
un total de ocho, realizadas a movimientos sociales, decisores políticos y personas vinculadas al TCP, para dar una visión integral sobre los avances y deudas pendientes en materia de protección al derecho a la vivienda en Bolivia.

Palabras clave: desarrollo, jurisprudencia, vivienda, ruptura.

ABSTRACT: The following work takes a normative and jurisprudence course on the right to housing that has occurred in the Plurinational State of Bolivia since the entry into force of the Plurinational Constitution of the State of 2009 and the Plurinational Constitutional Court (TCP).

The research aims to assess whether the normative changes included in the Constitution, considered to be at the same time as being at the same time as liberal vision and which assess the right to housing as justifiable, have had a correlation in practice with the delivery of justice at the height of magna carta. To do this, we will carry out an analysis of the case-law at the quantitative level, of the total number of decisions issued by TCP, and qualitative deepening the arguments of the judgments considered emblematic in terms of protection and guarantee of the right to housing. The work will be accompanied by interviews, a total of eight, conducted on social movements, political makers and people linked to TCP to give a comprehensive view on outstanding progress and debts in the protection of the right to housing Bolivia.

Keywords: development, jurisprudence, housing, breakup.

RÉSUMÉ: Les travaux suivants suivent un cours normatif et de jurisprudence sur le droit au logement qui a eu lieu dans l'État plurinational de Bolivie depuis l'entrée en vigueur de la Constitution plurinationale de l'État de 2009 et de la Cour constitutionnelle plurinationale (TCP).

La recherche vise à évaluer si les changements normatifs inclus dans la Constitution, considérés comme étant en même temps que la vision libérale et qui évaluent le droit au logement comme justifiable, ont eu une corrélation dans la pratique avec la prestation de la justice au plus fort de la magna carta. Pour ce faire, nous procéderons à une analyse de la jurisprudence au niveau quantitatif, du nombre total de décisions rendues par TCP et à l'approfondissement qualitatif des arguments des arrêts jugés emblématiques en termes de protection et de garantie du droit au logement. Les travaux seront accompagnés d'entretiens, d'un total de huit, menés sur les mouvements sociaux, les décideurs politiques et les personnes liées au PCC afin de donner une vue d'ensemble 
des progrès et des dettes en suspens dans la protection du droit au logement en Bolivie.

Mots-clés: développement, jurisprudence, logement, rupture.

SuMARIO: I. El nuevo enfoque de los derechos sociales. II. El desarrollo de politicas públicas relacionadas con la vivienda. III. Análisis de la jurisprudencia del Tribunal Constitucional Plurinacional en materia de vivienda. IV. Conclusiones.

V. Bibliografía.

\section{EL NUEVO ENFOQUE \\ DE LOS DERECHOS SOCIALES}

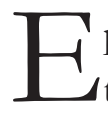
1 modelo de Estado que se instaura tras la entrada en vigor de la Constitución Política del Estado (CPE) de 2009 constituye una ruptura con el marco constitucional establecido en Bolivia desde el nacimiento de la República y su primera carta magna de 1826.

Las características del nuevo modelo constitucional, tal y como establecen los autores Soraya Santiago y Humberto Guarayo, serán las siguientes: la plurinacionalidad, el carácter comunitario del Estado, la descolonización, el pluralismo jurídico igualitario, la interculturalidad y el vivir bien como valor y principio del Estado. El artículo 1o. de la Constitución define de forma concreta el tipo de Estado al que se aspira:

Bolivia se constituye en un Estado Unitario Social de Derecho Plurinacional Comunitario, libre, independiente, soberano, democrático, intercultural, descentralizado y con autonomías. Bolivia se funda en la pluralidad y el pluralismo político, económico, jurídico, cultural y lingüístico, dentro del proceso integrador del país.

Al igual que en el resto de las Constituciones pertenecientes al nuevo constitucionalismo latinoamericano, ${ }^{2}$ una de las características más sobresalientes de los nuevos textos constitucionales es el hecho que no se establezcan jerar-

2 El concepto de nuevo constitucionalismo latinoamericano es definido en otros capítulos de la presente obra; y estos rasgos generales, en cuanto al tratamiento e importancia de los derechos humanos, coinciden con las otras dos Constituciones pertenecientes a esta corriente: 
quías entre los distintos derechos tal y como expresamente impone el artículo 13 de la Constitución. En dicho artículo se constata ${ }^{3}$ que todos los derechos son "inviolables, universales, indivisibles y progresivos". Igualmente se establece que los derechos humanos contemplados en la Constitución "no serán entendidos como negación de otros derechos no enunciados". Este mandato de la Constitución deja la puerta abierta a lo que podría considerarse como un poder constituyente continuado, ya que los nuevos derechos humanos que vayan surgiendo o las interpretaciones más favorables en esta materia son las que debieran prevalecer. Este artículo, fundamental en la interpretación de los derechos humanos, debe tomarse consideración con "la directa justiciabilidad de los derechos que ha sido considerada en el artículo 109 de la Constitución Plurinacional del Estado (CPE).

\section{Los derechos fundamentales}

Pese a la falta de jerarquía, la Constitución boliviana establece como fundamentales un grupo de derechos, entre ellos, el derecho a la vivienda objeto de nuestro estudio. Como explica el profesor Albert Noguera, denominar a ciertos derechos como fundamentales "es una diferenciación que sólo es útil a paradigmas ideológico-políticos de negación parcial de derechos, pero no a modelos basados en la indivisibilidad e interdependencia de los derechos". ${ }^{4}$

La clasificación como derechos fundamentales puede constituir también una referencia muy engañosa, pues en Bolivia distintos constitucionalistas, como Wilman Durán, ex presidente del Tribunal Constitucional previo al Tribunal Constitucional Plurinacional (TCP) establecido por la Constitución de 2009, caracterizaban los derechos fundamentales siguiendo a autores españoles de corte liberal, como Peces Barba y López Guerra, con "una base común de la cual parten todas las constituciones de nuestra órbita de cultura: la ordenación jurídica de la libertad".

Además, en la constitución de 2009, la denominación de derechos fundamentales aparece en dos momentos, primero en el título II, denominado

Venezuela y Ecuador. Jiménez S., Hacia la construcción plural del derecho desde la cosmovisión de la Nación Yampara, Bolivia, Konrad Adenauer Stiftung, 2014, p. 21.

3 Caso Covipol, 0897/2013, Tribunal Constitucional Plurinacional, 20 de junio de 2013.

4 Noguera, A., Los derechos sociales en las nuevas Constituciones latinoamericanas, Valencia, Tirant lo blanch, 2010, p. 175. 
"Derechos fundamentales y garantías". Por fundamentales entonces se entiende el conjunto de todos los derechos contemplados en la Constitución. En este momento, la definición de los derechos fundamentales encajaría con la definición de Luigi Ferrajoli que se desvincula de las concepciones liberales al considerar como fundamentales:

Todos aquellos derechos subjetivos que corresponden universalmente a "todos" los seres humanos en cuanto dotados del status de personas, ciudadanos o personas con capacidad de obrar; entendiendo por "derecho subjetivo" cualquier expectativa positiva (de prestaciones) o negativas (de no sufrir lesiones) adscrita a un sujeto por una norma jurídica; y por status la condición de un sujeto, prevista asimismo por una norma jurídica positiva, como presupuesto de su idoneidad para ser titular de situaciones jurídicas y/o autor de los actos que son ejercicio de éstas. ${ }^{5}$

En segundo lugar, encontramos la referencia "derechos fundamentales", en el capítulo II del mencionado título II, que comprende entre los artículos 15 y 20 de la Constitución. Entre los derechos denominados específicamente como fundamentales además de la vivienda, encontramos derechos como la vida y la integridad física, ${ }^{6}$ la alimentación, ${ }^{7}$ la educación, ${ }^{8}$ la salud, ${ }^{9}$ y los servicios básicos. ${ }^{10}$

A primera vista esta diferenciación con el resto de los derechos contemplados en la Constitución iría orientada a destacar el núcleo duro de los derechos que deben ser protegidos y garantizados, y una forma de honrar ciertas deudas sociales históricas. Sin embargo, esta nueva diferenciación que señala ciertos derechos como "fundamentales", crea cierto ruido y confusión, y por lo tanto la elección del término fue desafortunada. Mientras en Ecuador se optó por utilizar una nomenclatura apartada de la tradición del positivismo y próxima a visiones decoloniales, al denominarlos derechos del "buen vivir", en Bolivia se adoptó un vocablo procedente de la tradición doctrinal liberal.

5 Ferrajoli, L., Derechos y garantías. La ley del más débil, Madrid, Trotta, 1999, p. 37.

6 Artículo 15. CPE.

7 Ibidem, artículo 16.

8 Ibidem, artículo 17.

9 Ibidem, artículo 18.

10 Ibidem, artículo 20, entre los servicios básicos se entiende el agua potable, alcantarillado, electricidad, gas domiciliario, postal y telecomunicaciones. 
Aunque se optó finalmente por llamarlos derechos fundamentales, durante las discusiones en la Asamblea Constituyente, los integrantes del partido de gobierno Movimiento al Socialismo (MAS) plantearon denominar el mencionado grupo de derechos como fundamentalísimos, que respondía, proscritas las jerarquías, a un criterio de interpretación constitucional para que en el caso de conflicto de derechos constitucionales la balanza se inclinara a su favor. ${ }^{11} \mathrm{La}$ falta de una mayoría cualificada de constituyentes del MAS hizo que éstos tuvieran que ceder a la solicitud de la oposición de no utilizar el término derechos fundamentalísimos, aunque sus motivaciones respondían a criterios de forma y lo enrevesado que sonaría el vocablo. ${ }^{12}$

El título II de la Constitución de 2009 quedó conformado finalmente por los siguientes capítulos: Derechos fundamentales (capítulo II), Derechos civiles y políticos (capítulo III), Derechos de las naciones y pueblos indígenas originarios campesinos (capítulo IV), y Derechos sociales y económicos (capítulo $\mathrm{V}$ y VI). El derecho a la propiedad privada ${ }^{13}$ se encuentra ubicado en la sección IV del capítulo $\mathrm{V}$ dedicado a los derechos sociales y económicos, de manera que en principio, en caso de conflicto con el derecho a la vivienda, ubicado junto a los derechos fundamentales, prevalecería este último. En consecuencia, la protección extra del derecho a la vivienda como derecho fundamental se corresponde con la intención rupturista frente a prácticas jurídicas liberales que consideran como fundamentales, y por lo tanto justiciables únicamente las libertades individuales o burguesas.

Por último, el TCP en la sentencia 0892/2013 también ha manifestado su parecer en relación con aquellos derechos que por ubicación e importancia denomina como fundamentales-fundamentales:

Este grupo de derechos; por tanto, bajo la estructura constitucional tiene la calidad de derechos "Fundamentales-Fundamentales"; doble fundamentalidad que responde tanto a la ubicación de éstos en la Constitución Política del Estado, como a los contenidos que el constituyente le asignó, bajo el entendido que son los mínimos indispensables que permiten a las personas y colectividades a desarrollarse plenamente y ejercer los otros derechos previstos en la Ley Fundamental.

11 Noguera, A., “¿Derechos fundamentales, fundamentalísimos o, simplemente, derechos? El principio de indivisibilidad de los derechos en el viejo y el nuevo Constitucionalismo". Derechos y Libertades, núm. 21, 2009, pp. 117-147; disponible en bttps:// bit.ly/3dHmHoJ.

12 Ibidem, p. 129.

13 Artículo 56, CPE. 


\section{La justiciabilidad de los derechos sociales}

Quizás el mayor avance en materia de derechos humanos bajo la CPE de 2009 tiene relación con la declaración de la justiciabilidad de todos los derechos reconocidos en el texto constitucional, independientemente de si son considerados derechos fundamentales o no. Esta es una de las características más sobresalientes de los textos que enmarcamos en el nuevo constitucionalismo latinoamericano. Para la exmagistrada del TCP, Ligia Velásquez la justiciabilidad de todos los derechos contemplados en la Constitución significó "una enorme responsabilidad", así como "el gran reto" durante su gestión. ${ }^{14}$

Primero, en el artículo 13.III se establece de manera expresa la inexistencia de "jerarquía alguna ni superioridad de unos derechos sobre otros"; para posteriormente en el artículo 109 afirmar explícitamente que "todos los derechos reconocidos en la Constitución son directamente aplicables y gozan de iguales garantías para su protección".

Pero la justiciabilidad no sólo es señalada en el texto constitucional, también ha tenido un desarrollo jurisprudencial. En la sentencia 1696/2014 referida al derecho al agua potable se trató este derecho desde dos perspectivas distintas: en primer lugar, como un derecho subjetivo, y dependerá "del titular o titulares individualmente considerados su correspondiente exigibilidad"; en estos casos la tutela del derecho debe efectuarse a través de la acción de amparo constitucional. En segundo lugar, los derechos pueden ser considerados, "en su dimensión colectiva, es decir, para una población o colectividad"; la tutela entonces corresponde mediante una acción popular. Que se considere sin cortapisas la perspectiva subjetiva e individual de los derechos sociales, como el derecho al agua en este caso, pero que también se entendería para el derecho a la vivienda, nos resulta una vez más una visión que pone en tela de juicio los posicionamientos liberales históricamente considerados, y genera un nuevo entendimiento de los derechos humanos.

\section{Antecedentes y evolución del derecho a la vivienda}

El derecho a la vivienda no estuvo de manera autónoma contemplado en la Constitución previa a la actual en Bolivia. La Constitución de 1967 con sus

\footnotetext{
14 Entrevista personal, 13 de marzo de 2018.
} 
reformas consideró únicamente la cobertura de la vivienda de interés social como parte del régimen de seguridad social. ${ }^{15}$

La máxima instancia judicial, el Tribunal Constitucional, podía resolver los recursos de amparo constitucional entre sus atribuciones, ${ }^{16}$ orientado a evitar la violación de los derechos. ${ }^{17}$ Pero el catálogo de los derechos fundamentales contemplados en la Constitución de 1967, se limitaba a un artículo con catorce apartados, en su mayoría de carácter civil y político, ${ }^{18}$ por lo que la protección de derechos era relativamente estrecha, especialmente en comparación con el texto constitucional que le sucedería en 2009. No obstante, durante el periodo de vigencia de la Constitución de 1967, fue importante el activismo judicial para garantizar ciertos derechos de carácter social como el derecho a la seguridad social o al trabajo. ${ }^{19}$

Para Albert Noguera, a la hora de abordar el desarrollo jurisprudencial del derecho a la vivienda, hay que advertir la "larga tradición [de Bolivia] de subordinación y lealtad de los jueces a los intereses del poder político y económico, tanto a nivel nacional como local" ${ }^{20}$ En el desarrollo del presente trabajo también se plantea tangencialmente la persistencia de la subordinación del TCP respecto a la tutela de los derechos civiles y políticos, según voces críticas.

\section{El derecho a la vivienda en la Constitución de 2009}

El artículo 19 contempla el derecho a la vivienda que ha quedado configurado en la Constitución boliviana de la siguiente manera: "Toda persona tiene derecho a un hábitat y vivienda adecuada, que dignifiquen la vida familiar y comunitaria". La CPE toma en consideración no sólo el derecho a la vivienda, sino también el hábitat.

En una segunda parte, este derecho establece la obligación del Estado de construir viviendas de interés social orientadas a familias de bajos recursos:

El Estado, en todos sus niveles de gobierno, promoverá planes de vivienda de interés social, mediante sistemas adecuados de financiamiento, basán-

\footnotetext{
15 Artículo 158 de la constitución de 1967.

16 Ibidem, artículo 120.7.

17 Ibidem, artículo 19.

18 Ibidem, artículo 7o.

19 Sauma, G., entrevista con Fernando Casado, 15 de marzo de 2018.

20 Noguera, A., Los derechos sociales..., cit., p. 186.
} 
dose en los principios de solidaridad y equidad. Estos planes se destinarán preferentemente a familias de escasos recursos, a grupos menos favorecidos $\mathrm{y}$ al área rural.

El derecho a la vivienda, tal y como ha sido finalmente conceptualizado en la CPE, estaría inspirado en los tratados internacionales y resoluciones de organismos internacionales como la Observación General No. 4 del Comité de Derechos Económicos, Sociales y Culturales, por el que se considera de manera amplia el derecho a la vivienda y la posibilidad de vivir en alguna parte en seguridad, paz y dignidad. ${ }^{21}$

Pero la introducción del derecho a la vivienda en la Constitución de Bolivia no proviene únicamente de una motivación técnico-jurídica, sino que es fruto de las luchas sociales y la presión de la sociedad civil. Anelise Meléndez, activista de la Red Hábitat, destaca la importancia de las llamadas guerra del agua y guerra del gas para posicionar el reconocimiento de los derechos sociales en el centro del debate social.

En el periodo comprendido entre los años 2000 y 2006, los esfuerzos de la Red Hábitat se centraron en la posibilidad de introducir una ley para el otorgamiento de subsidios en materia de vivienda para las personas más necesitadas, y que hasta ese momento se otorgaban de manera discrecional. Finalmente, durante el proceso constituyente, y tomando como referencia las propuestas de la Coalición Internacional del Hábitat, se hicieron grandes esfuerzos y cabildeo para que fuera introducido el derecho a la vivienda en la Asamblea Constituyente y la Constitución de 2009.22

Habría sido gracias a la Red Nacional de Asentamientos Humanos (RENASEH) y otros colectivos que se incluyó en la Constitución el concepto de vivienda adecuada y no simplemente digna, que sería el término correcto para la protección de este derecho. Como nos explica Anelise Meléndez para distinguir ambos conceptos:

Nosotros decimos que la vida es digna, pero la vivienda tiene que ser también adecuada, porque una vivienda adecuada para una persona soltera, es diferente que una vivienda adecuada para una persona que tiene 8 o 9 hijos,

21 Pinto, Y. C., La justiciabilidad y efectividad de los derechos económicos, sociales y culturales en el Estado boliviano, al amparo de la Constitución Política del Estado y los tratados de derechos humanos ratificados, Red de Profesionales Abogados en Derechos Humanos Capacitación y Derechos Ciudadanos, 2012, p. 22.

22 Entrevista personal, 13 de marzo de 2018. 
yo me puedo contentar con un dormitorio y no estar hacinados si estoy solo o estoy con mi pareja, pero cuando tengo 8 hijos y tengo un dormitorio, no es adecuado porque estás vulnerando uno de los principios del derecho, que es la habitabilidad y que tiene que ver con un indicador medible que es el hacinamiento. ${ }^{23}$

\section{El Tribunal Constitucional Plurinacional}

Desde la entrada en vigor de la Constitución de 2009, es el TCP el encargado de ejercer el control de constitucionalidad y precautelar el respeto de los derechos y garantías constitucionales. ${ }^{24}$ Las magistradas y magistrados que componen el TCP son elegidos bajo criterios de plurinacionalidad, con representación del sistema ordinario de justicia y del sistema indígena originario campesino. ${ }^{25}$ Debemos tener en cuenta a la hora de abordar el sistema judicial boliviano, que éste será de carácter mixto, lo que implica que no sólo los magistrados del TCP, sino todos los jueces realizan el control de constitucionalidad, la aplicación de los derechos fundamentales, el control de convencionalidad, y la aplicación de los tratados internacionales. ${ }^{26}$

El TCP es el órgano que se ocupa de la revisión de las acciones de libertad, de amparo constitucional, de protección de privacidad, popular y de cumplimiento. ${ }^{27}$

En nuestra investigación, relacionada con la implementación del derecho a la vivienda, nos interesa el estudio de las acciones de amparo constitucional, que impedirán que se "restrinjan, supriman o amenacen restringir o suprimir los derechos reconocidos por la Constitución y la ley"; 28 de las acciones populares, cuando se amenace con violar derechos e intereses colectivos, ${ }^{29}$ y de las acciones de cumplimiento, "para garantizar la ejecución de la norma emitida".30

Las acciones de amparo y las populares podrán interponerse ante la violación tanto de los derechos constitucionales contemplados en la Constitución,

23 Entrevista personal, 13 de marzo de 2018.

24 Artículo 196, CPE.

25 Tribunal Supremo Electoral, Compendio Electoral del Estado Plurinacional de Bolivia. Servicio Intercultural de Fortalecimiento Democrático, 2009, p. 47.

26 Pinto, Y. C., op. cit., p. 70.

27 Artículo 202.6. CPE.

28 Ibidem, artículo 128.

29 Ibidem, artículo 135.

30 Ibidem, artículo 134. 
como los derechos humanos contemplados en los tratados internacionales ratificados por Bolivia. ${ }^{31}$ La acción de amparo otorga a la persona la facultad de activar la justicia frente a los actos u omisiones de los servidores públicos o particulares..$^{32}$ Por su parte, el reconocimiento de la acción popular significa un avance cualitativo respecto al ejercicio de los derechos, especialmente de las naciones y pueblos indígenas originarios campesinos. ${ }^{33}$

Una de las mayores originalidades del TCP en el plano comparativo es que los miembros de este tribunal son elegidos mediante sufragio universal. ${ }^{34} \mathrm{No}$ hay otro país en el mundo que contemple una fórmula similar para la elección de sus magistrados, y aunque este sistema responde a evitar la influencia de intereses espurios, provoca sentimientos encontrados. Una de las críticas señala que las personas más preparadas en cuanto al conocimiento de derecho constitucional no habrían participado del proceso, y algunos de los postulantes que resultaron elegidos como magistrados no eran especialistas en la materia. Esto habría ocurrido como consecuencia de que, tras el proceso constituyente, muchos intelectuales, indígenas ecologistas y técnicos que en un primer momento apoyaron al gobierno lo habrían ido abandonando, entre ellos juristas. ${ }^{35}$

Como nos explica la letrada del TCP Gabriela Sauma, la protección de los derechos honrados en la Constitución boliviana va a depender en gran medida "de la posición que tengan los magistrados, de la apertura, del compromiso y hasta de la orientación política que tengan frente a los derechos humanos". ${ }^{36}$ La protección de los derechos, por tanto, va a depender no sólo del marco normativo sino de la subjetividad del magistrado que revise una causa determinada. En consecuencia, han habido causas en las que antes que la justiciabilidad ha primado criterios de carácter formal, dejándose en ocasiones en situación de violación, sus derechos a grupos vulnerables. Además, el tribunal transitorio, que habría sido el primero encargado de desarrollar los derechos contemplados en la Constitución, llevó a cabo una aplicación de "criterios restrictivos". ${ }^{37}$

31 (n.d.). p. 61.

32 Vargas, A., "La acción de amparo constitucional en Bolivia", en Herrera. W., (ed.), Las acciones de defensa y el control de convencionalidad en Bolivia, Kipus, 2017, p. 41.

33 Sotillo, A., "Desarrollo jurisprudencial de la acción popular en Bolivia", en Herrera, W., Las acciones de defensa y el control de convencionalidad en Bolivia, Kipus, 2017, pp. 269-292.

34 Artículo 196, CPE.

35 Sauma, G., Entrevista con Fernando Casado,15 de marzo de 2018.

36 Idem.

37 Idem. 
Existen opiniones, como la de la consultora Soraya Santiago, que afirman que el llamado tribunal de los diez años, previo a la creación del TCP, fue más garantista y existió, con un mayor activismo jurídico que el actual TCP. ${ }^{38}$ Sin embargo, otras voces, como la de Gabriela Sauma, tienen un planteamiento crítico, pues estos magistrados "estaban comprometidos con la justicia constitucional, pero bastante limitada a los derechos individuales" y no existiría aun un compromiso con los derechos sociales. ${ }^{39}$

Ahora bien, desde el punto de vista de Gabriela Sauma, pese a que el marco normativo bajo la Constitución de 2009 es mucho más progresista que el anterior, y existe la clara intencionalidad de abrir la protección constitucional no sólo a los derechos individuales, sino a todos los contemplados en la Constitución, incluido los colectivos y difusos, con el nuevo Tribunal Constitucional se habría producido un retroceso a nivel técnico en cuanto al trabajo desempeñado por los magistrados del TCP.40

Dicha situación tendría una relación directa con el hecho de que el proceso de selección de los magistrados habría estado muy politizado e influenciado por el Poder Ejecutivo. ${ }^{41}$ Para la exmagistrada Ligia Velásquez, el partido de gobierno siempre tuvo una holgada mayoría en la Asamblea Legislativa Plurinacional, por lo que se ha acabado eligiendo "a las personas allegadas al partido de gobierno". ${ }^{42}$ Esta situación comprobamos que es similar en las democracias occidentales, en las que el partido mayoritario en los poderes Legislativo y Ejecutivo, independientemente de si es un sistema de gobierno presidencial o parlamentario, acaba imponiendo su hegemonía también en el Poder Judicial. Sin embargo, para su caso concreto, Ligia Velásquez expresó que el sistema de preselección fue "imparcial", pues nunca tuvo filiación política alguna y simplemente respondió a la convocatoria para postularse como magistrada del TCP. ${ }^{43}$

En diciembre de 2017 se celebró la segunda elección por voto universal directo en la historia de Bolivia de los 52 magistrados elegidos entre los más altos tribunales de una lista de 96 personas preseleccionadas por la Asamblea Legislativa Plurinacional, con base a sus méritos académicos y

\footnotetext{
38 Entrevista personal, 14 de marzo de 2018.

39 Sauma, G., Entrevista con Fernando Casado de 15 de marzo de 2018.

40 Idem.

41 Idem.

42 Entrevista personal, 13 de marzo de 2018.

43 Idem
} 
laborales, mediante una forma sui generis de elegir a los candidatos, pues éstos no están facultados para realizar ningún acto de campaña por su candidatura, sino que es el Consejo Nacional Electoral el organismo encargado de promocionarlos.

Aunque se puede considerar como muy positiva la iniciativa directa de los miembros del TCP, lo cierto es que el proceso no contó con el apoyo popular mayoritario, pues en un país en el que el voto es obligatorio, en los nueve departamentos bolivianos los votos nulos y blancos superaron el $50 \%{ }^{44}$

El proceso de selección de los magistrados ha sido criticado por considerarse que fue monitoreado desde el gobierno (Gabriela Sauma, Soraya Santiago) y con miras a influenciar el tutelaje de ciertos derechos, sobre todo en los relacionados con derechos civiles y políticos. Como consecuencia, los magistrados del TCP tendrían miedo de actuar e intervenir en causas fuertemente politizadas, ya que el "proceso penal ha sido utilizado como un arma contra la disidencia, entonces efectivamente los jueces actuales ya no quieren tutelar esos derechos, porque al hacerlo, tutelan a los disidentes, y eso implica tener consecuencias nefastas contra ellos". ${ }^{45}$

De hecho, el miedo de los magistrados no es infundado, en el año 2014 la magistrada Ligia Velásquez, elegida en el año 2011 en la primera cohorte de magistrados por votación popular, renunció a su cargo después de que se iniciara por la Asamblea Legislativa Plurinacional un juicio penal por responsabilidad. El juicio en su contra, junto con dos magistrados más, se habría iniciado después de haber emitido un auto constitucional de admisión por el planteamiento de un diputado de la inconstitucionalidad de una norma promulgada por el Ejecutivo que trasladaba ciertas funciones jurisdiccionales en manos de los jueces hasta ese momento (divorcios, sucesiones hereditarias, autorizaciones judiciales de viaje, funciones netamente jurisdiccionales) a los notarios, bajo la órbita de control del Poder Ejecutivo (entrevista personal, Ligia Velásquez, 13 de marzo de 2018). La admisión del auto constitucional fue además acompañada de una medida cautelar que suspendía la norma, lo que según la afectada habría desatado todo un proceso en su contra que buscaba un castigo ejemplar que sirviera de amedrentamiento al conjunto de los jueces a futuro, y que acabó con la renuncia de la exmagistrada Ligia Velásquez y sus dos colegas.

44 Conoce los resultados del Tribunal Constitucional, El Deber, 3 de Diciembre de 2017; disponible en https:// bit.ly/3dDNGBf.

45 Entrevista personal, 15 de marzo de 2018 


\section{EL DESARROLLO DE POLÍTICAS PÚBLICAS RELACIONADAS CON LA VIVIENDA}

Para la organización Capítulo Boliviano de Derechos Humanos, Democracia y Desarrollo, la vivienda ha sido uno de los temas menos priorizados en las dos décadas previas a la entrada en vigor de la Constitución de 2009, con políticas de dotación de viviendas a través de políticas crediticias y con presupuestos insuficientes. Esta falta de políticas públicas tuvo como consecuencia que entre 1996 y 2006 la tenencia de viviendas de la familia disminuyera en más del 5\%, "mostrando una clara falta de apoyo o respaldo de otros derechos colaterales como el derecho al trabajo, al salario justo, a un nivel de vida digno, etc. El derecho a la vivienda es una variable dependiente de otras".

A raíz de la llegada al poder de Evo Morales y la aprobación de la Constitución de 2009, se desarrollaron gran cantidad de políticas públicas para asegurar la garantía del derecho a la vivienda que son, por mandato constitucional, "competencias privativas del nivel central del Estado". ${ }^{46}$ A partir de 2006 se crea el Programa de Vivienda Social y Solidaria (PVSS) que "combina aportes privados y estatales, formas de crédito y de subsidio para el financiamiento de vivienda a la población carente". ${ }^{47}$ Esta iniciativa estaría entre las primeras para incrementar el acceso a la vivienda, aunque como el mismo Ministerio reconoce, se trabajaba con los sectores sociales que ejercían presión para imponer sus proyectos, sin tener en cuenta los déficits habitacionales de cada zona geográfica, las necesidades reales de los beneficiarios o el carácter solidario del programa. Sin embargo, con el mencionado plan se pretendía la construcción de viviendas nuevas y mejoramiento, con créditoss y subsidios directos. ${ }^{48}$

El TCP también se ha referido a las políticas públicas desarrolladas por el Poder Ejecutivo en Bolivia, como el PVSS, y en la sentencia 0426/2012 señaló que este plan va dirigido a "atender las necesidades habitacionales de la población de menores ingresos económicos, generando mecanismos legales que permitan el acceso de la población a una vivienda digna bajo preceptos de equidad social". En la misma sentencia también afirmó el tribunal que:

\footnotetext{
46 Artículo 298. II. 36 de la CPE.

47 Construyendo comunidades urbanas para vivir bien en el siglo XXI. Informe del Estado Plurinacional de Bolivia para hábitat III, Ministerio de Obras Públicas (ed.), 2016, p. 82

48 Idem.
} 
...merece exigir su cumplimiento en aras de la construcción de una sociedad plural sustentada en los principios ético-morales del suma qamaña (vivir bien), ñandereko (vida armoniosa), tekokavi (vida buena), ivimaraei (tierra sin mal) y qhapajñan (camino o vida noble), conforme prevé el artículo 8.I de la CPE.

El tribunal, en primer lugar, reconoce la necesidad de desarrollar políticas públicas orientadas a la satisfacción del acceso al derecho a la vivienda, especialmente a las personas que estén en una situación más vulnerable; y, en segundo lugar, funda su cumplimiento en una cosmovisión previa a la llegada de los occidentales y la sociedad plurinacional que está en proceso de consolidación en Bolivia.

Las políticas públicas fueron posteriormente evolucionando y tratando de corregir los primeros errores identificados, de esta forma fue creada en 2011 la Agencia Estatal de Vivienda, que tendría a su cargo proyectos integrales de dotación de vivienda a nivel nacional con base al Plan Plurianual de Reducción de Déficit Habitacional. Los ingresos para la aplicación de los planes provendrían "del 2\% del aporte patronal y priorizando la atención de familias de menores ingresos y grupos vulnerables". ${ }^{49}$ Como resultado se ha ido incrementado la construcción de viviendas por iniciativa estatal, "de un promedio de 1600 viviendas anuales en el periodo 2001-2005, se ha llegado a una producción de 12424 viviendas en el periodo 2010-2015". ${ }^{50}$ Éste es un incremento importante si se tiene en cuenta que entre el 2006-2010 el número total de viviendas construidas en el lustro habría alcanzado las $26000 . .^{51}$ Éstas metas estarían incrementándose, y si en la primera década del gobierno se construyeron un total de 100000 viviendas, es decir, entre el año 2006 y hasta el 2016, para el año 2020 el objetivo sería incrementar dicha cifra (Radio Habana, Cuba, 2017). El incremento en la construcción de viviendas de protección social por el Estado se habría situado en el año 2017 en 25 000, y la intención desde el Viceministerio de Vivienda es mantener en los años sucesivos este mismo nivel. ${ }^{52}$ Tales planes vendrían a paliar el déficit cuantitativo en materia de vivienda que para el año 2010 se situaba en $200000 .^{53}$

\footnotetext{
49 Ministerio de Obras Públicas (ed.), op. cit., p. 82.

50 Idem.

51 ABI., Gobierno promete construir 100 mil viviendas hasta 2015 y eliminar déficit habitacional en Bolivia, Eju!, 8 de octubre de 2011; disponible en bttps:/ / bit.ly/3upyBdA.

52 Entrevista personal, 11 de marzo de 2018.

53 Renaseh, Informe: Derecho Humano a la Vivienda en Bolivia. Examen Periódico Universal, 2010.
} 
Las políticas públicas están orientadas a hacer frente al déficit cuantitativo de viviendas, es decir, otorgar viviendas a las personas que no tienen ningún acceso a ellas, y para esos casos extremos existen programas de subsidios. Pero también se trata de paliar el déficit cualitativo, para aquellas personas a las que se les va a ayudar desde el Estado a mejorar las condiciones de su vivienda, y para estos casos existe un sistema mixto donde Estado y beneficiario financian una parte. Por último, para la adquisición de vivienda en zonas urbanas el Estado estaría otorgando créditos por un monto total de hasta 120 mil dólares a tasas de interés de entre un $5 \%$ y $6 \%$, que son mucho más bajas que las que se obtienen en el mercado privado. ${ }^{54}$

También se han visto mejorías en el acceso a los distintos servicios en Bolivia, según el Instituto Nacional de Estadística, si el acceso al servicio de cañerías era del $62.3 \%$ en 2001, para el 2012 casi un millón de personas habrían accedido al servicio que se situaría en $68.3 \%$. En cuanto al acceso al agua potable se situaría en $52.7 \%$, es decir, 11.3 puntos más que en el 2001.55

Pese a estos logros, Abraham Apaza, arquitecto en el Viceministerio de Vivienda y Urbanismo de Bolivia, reconoce que han aplicado "soluciones parche" pero sin atacar los problemas estructurales. ${ }^{56} \mathrm{La}$ incapacidad para desarrollar políticas de carácter estructural tendría relación con la alta conflictividad social que ha llegado al punto de incendiar alcaldías por el mero anuncio del levantamiento de un catastro urbano, de carácter necesario ante los altos niveles de informalidad en la ocupación de terrenos existentes, lo que impide la operativización de planes de planificación urbana. Pero otro de los problemas es la falta de legislación en la materia, de un "recurso natural no renovable como el suelo", por lo que en cuanto a tierras urbanas impera una total ley del mercado en la actualidad. ${ }^{57} \mathrm{La}$ misma falta de regulación se produce en materia de regulación de las plusvalías de bienes inmuebles, y en relación con el alquiler de vivienda, la Ley del Inquilinato vigente en Bolivia es de 1959. En consecuencia, existirían altos niveles de especulación en los precios para el acceso a la vivienda.

En el año 2012 se elaboraron normativas como la ley 247 y la ley 803, dirigidas a la regularización justamente del derecho propietario de la vivienda que ha tenido su posesión pacífica por lo menos durante cinco años previos

\footnotetext{
54 Vargas, M., Entrevista con Fernando Casado de 12 de Marzo de 2018.

55 Instituto Nacional de Estadística (ed.), Estadisticas en construcción de vivienda; 2017.

56 Entrevista personal, 11 de marzo de 2018.

57 Idem.
} 
a la entrada en vigor de la ley en áreas urbanas homologadas y donde los municipios hayan delimitado las tierras urbanas. Pero como relató Apaza, estos instrumentos "no están rindiendo los resultados operativos que esperábamos, porque muchos municipios no han definido ni siquiera su área urbana". ${ }^{58}$

Por último, hay que mencionar que las políticas públicas desarrolladas están orientadas a colaborar con el sector privado, que juega un rol fundamental en el sector de la construcción en Bolivia. Desde el Viceministerio de la Vivienda se quiere continuar con que permitan el desarrollo y autonomía del sector privado, pero con la condición, según Apaza, "que tienen un poco que retornarnos, más o menos con ese principio queremos trabajar, porque es pelearse con el $80 \%$ de la población que es informal". ${ }^{59}$

\section{Las críticas de los movimientos sociales a la política pública}

Pese a los avances normativos en materia de vivienda y las políticas públicas alegadas por el gobierno, son muchos los autores críticos que han calificado como insuficiente el desarrollo del derecho, especialmente desde la sociedad civil.

Una de las críticas al PVSS es precisamente que estuviera alejado de los problemas prioritarios de Bolivia en materia de vivienda que serían principalmente de acuerdo con el Foro Permanente de la Vivienda (FOPEVI):

...de carácter cualitativo reflejado en las condiciones de precariedad, hacinamiento, inseguridad jurídica, deficiencias en los servicios básicos, falta de infraestructura urbana que caracterizan los asentamientos populares impulsados por procesos autogestionarios de la construcción de la vivienda y ciudad (Fopevi, 2009:10).

La Renaseh coincide con esta lectura al afirmar que el PVSS atendió principalmente la vivienda nueva a la que destinó el 70\% de sus recursos y tan sólo el 30\% a los problemas de tipo cualitativo, como el mejoramiento de las condiciones de habitabilidad del parque autoproducido, que en total constituiría el 46\% de las viviendas en Bolivia, alrededor de un millón. ${ }^{60}$ Esta misma organización también criticó al PVSS por ser para 2010 la única oferta guber-

\footnotetext{
58 Idem.

59 Idem.

60 Renaseh (ed.), op. cit.
} 
namental en atención a la vivienda que privilegió a las "entidades financieras y empresas constructoras con fines de lucro y altas expectativas de rentabilidad económica", lo que provocó el afianzamiento del enfoque de mercado y el modelo económico neoliberal. ${ }^{61}$

Existen también críticas a la manera en que habrían sido utilizados los recursos de vivienda, "con un criterio clientelar, de compensar favores de voto". ${ }^{2}$ Según esta visión, la vivienda habría sido utilizada como un "comodín para acallar y tratar de resolver problemas de carácter sindical y gremial". En algunas ocasiones, además el propio Estado se ha comportado como lo hacen los especuladores del suelo, en primer lugar, comprando el suelo a precios de mercado especulativo; y en segundo lugar, construyendo viviendas de protección social que son vendidas por encima del costo de construcción. ${ }^{63}$

Hasta ahora, para académicos como Sonia Jiménez, no se habrían cumplido las promesas en materia de vivienda, existiendo una notoria discrepancia entre los compromisos asumidos y la voluntad política de cumplirlos. El incumplimiento puede atribuirse a obstáculos económicos, tecnológicos e institucionales en esferas gubernamentales, ausencia de una buena gobernabilidad y simplificación de los procedimientos, así como a la falta de mecanismos eficaces de gestión y ejecución. ${ }^{64}$

Entre los muchos problemas identificados, Jiménez infiere que hay "sectores populares que no cuentan con vivienda porque no tienen acceso al mercado de suelo, a subsidios y créditos para la compra de lotes, porque no hay provisión de tierras urbanizadas por el Estado". ${ }^{65} \mathrm{Al}$ mismo tiempo, no hay una regulación de los precios del suelo y vivienda, lo que provoca que existan altos niveles de especulación en el sector inmobiliario. ${ }^{66}$

Frente a esta realidad de falta de desarrollo y cumplimiento de las políticas públicas en materia de vivienda, los movimientos sociales han hecho un uso deficitario del denominado litigio estratégico, con el que podrían interponer acciones judiciales frente al Estado. Como podremos observar en el análisis jurisprudencial, existe una ausencia de demandas impulsadas por los movi-

\footnotetext{
61 Idem.

62 Meléndez, Anelise, Entrevista personal, 13 de marzo de 2018.

63 Idem.

64 Jiménez, S., "Por el reconocimiento y justiciabilidad del derecho humano a la vivienda en Bolivia", INVI 23 (62), 2008; pp. 99-125; disponible en bttps:/ / bit.ly/39Lg2Z8.

65 Jiménez, S., La cuestión socio habitacional en Bolivia. Actualización de datos censales en base a los resultados oficiales publicados por el INE en agosto del 2014, INE, 2014.

66 Saavedra, S., Entrevista con Fernando Casado, 12 de marzo de 2018.
} 
mientos sociales organizados para reivindicar el derecho justiciable a la vivienda, lo que constituye una diferencia importante con otros países pertenecientes al nuevo constitucionalismo latinoamericano, como Venezuela. Para la exmagistrada del TCP, Ligia Velásquez, uno de los motivos sería que "todavía hay un desconocimiento de cuáles son sus derechos y eso es por falta de acceso a la justicia". ${ }^{67}$ Sin embargo, cabe destacar que los movimientos sociales, como la Fundación Construir, también reconocen que la línea del TCP ha estado muy orientada a la protección y garantía del derecho a la vivienda, "que la persona tenga, por lo menos, un techo donde vivir". ${ }^{68}$

\section{ANÁLISIS DE LA JURISPRUDENCIA DEL TRIBUNAL CONSTITUCIONAL PLURINACIONAL EN MATERIA DE VIVIENDA}

A partir de este momento, la investigación se centrará en el análisis jurisprudencial del desarrollo del derecho a la vivienda en Bolivia. En una primera parte se hará un recuento cuantitativo del número de sentencias emitidas por el TCP, para analizar posteriormente algunas de las sentencias emblemáticas referidas a distintos temas y aspectos del derecho a la vivienda tutelados por el alto tribunal.

\section{Análisis cualitativo de la jurisprudencia del Tribunal Constitucional Plurinacional}

Como veremos a continuación, la mayoría de las sentencias hace referencia a la protección del derecho a la vivienda y el hábitat en relación con vías de hecho y desapoderamiento que se producen cuando el propietario del inmueble se toma la justicia por su propia mano frente a quien posee su tenencia. En estos casos podremos ver distintas estrategias desarrolladas por el TCP para limitar el abuso del ejercicio de la propiedad privada y la protección de las personas, especialmente aquellas que se encuentren en una situación de vulnerabilidad.

Pero el tribunal tiene también una importante trayectoria a través de su jurisprudencia en cuanto a la definición expansiva del derecho a la vivienda; el establecimiento de la obligatoriedad del cumplimiento del Estado con el

\footnotetext{
67 Entrevista personal, 13 de marzo de 2018.

68 Loayza, Marco, Entrevista personal, 12 de marzo de 2018.
} 
desarrollo de sus políticas públicas; la defensa del hábitat de los pueblos originarios, y la protección de grupos vulnerables frente al riesgo de desalojo de una vivienda. Todos estos casos serán analizados a continuación.

\section{La aplicación del estándar más alto de la jurisprudencia constitucional}

Una de las sentencias emblemáticas de TCP es la 2233/2013, estableció que siempre, en caso de controversia, se deben aplicar las normas y estándares en materia de derechos humanos más altos y favorables. Esta sentencia referida a una acción de libertad interpuesta por un allanamiento judicial plantea concretamente cómo llevar a cabo la interpretación de la Constitución y de los tratados internacionales de derechos humanos que forman parte del bloque de constitucionalidad: "El método de identificación del estándar más alto en la jurisprudencia constitucional es a través de un examen o análisis integral de la línea jurisprudencial, de tal forma que el precedente constitucional en vigor se constituirá en aquél que resulte de dicha comparación”.

La manera de determinar el estándar más favorable será, en primer lugar, mediante la elección de la sentencia más adecuada en caso de que sean contradictorias; y, en segundo lugar "de existir diversos entendimientos jurisprudenciales no antagónicos sino progresivos, los mismos deben armonizarse para la resolución más adecuada del caso en atención a los derechos fundamentales".

La sentencia 2233/2013 es importante para armonizar la jurisprudencia del TCP, porque en ocasiones fue "ondulante" e incluso "contradictoria", tal y como nos relató la exmagistrada Ligia Velásquez, debido a que cada sala y cada magistrado actuaban de manera independiente. ${ }^{69}$

En realidad, el principio de aplicación del estándar más alto se contempla en la Constitución en los artículos 256 y 13, IV, ${ }^{70}$ pero su inclusión jurisprudencial podría tener como resultado que sea más difícil dictar sentencias de carácter regresivo o politizar a la Corte. Para lograr la armonización de la jurisprudencia y poder aplicar los estándares más altos, se está llevando a cabo la sistematización de la jurisprudencia del Tribunal Constitucional. No obstante, va a depender de cada magistrado la armonización de la jurisprudencia

69 Entrevista personal, 13 de marzo de 2018.

70 Artículo 256 II, CPE planea: "los derechos reconocidos en la Constitución serán interpretados de acuerdo con los tratados internacionales de derechos humanos cuando éstos prevean normas más favorables". 
para posteriormente aplicar los estándares más altos, y hasta el momento no todos lo estarían haciendo. ${ }^{71}$

\section{Los principios en materia de derechos humanos bajo los que actúa el Tribunal Constitucional Plurinacional}

El TCP en su accionar para proteger los derechos humanos, también ha establecido que debe actuar bajo dos principios: en primer lugar, aplicar siempre la regla pro homine, adoptando "la interpretación que sea más favorable y extensiva al derecho en cuestión"; y, en segundo lugar, ejerciendo el control de convencionalidad y conforme a los tratados internacionales de derechos humanos ratificados por Bolivia, que prevalecerán en el orden interno cuando establezcan normas más favorables. ${ }^{72}$

En su jurisprudencia, el TCP ha reconocido la exigibilidad y justiciabilidad directa que poseen todos los derechos fundamentales reconocidos en la CPE, lo que se correspondería con el mandato del artículo 109. En el Caso Servicio Departamental de Salud (Sedes) 0121/2012, el TCP exigió la superación de los plantamientos jurídicos iuspositivistas y formalistas que proponen únicamente la limitación del poder y "consagrar y consolidar la vigencia material de los derechos fundamentales", a través de su aplicación directa (p. 5). Esta posición se vio reforzada en el caso 0450/2012 cuando el tribunal estableció que siempre prevalecerá el "derecho material o sustantivo sobre las formalidades", con la constatación de los derechos fundamentales (p. 12).

Uno de los problemas más importantes a los que se enfrenta el TCP en la práctica es la falta de seguimiento y de cumplimiento de las sentencias emitidas, muchas de ellas en materia de protección de los derechos sociales, por lo que el tribunal recibiría numerosas quejas. ${ }^{73}$ Esta puede ser una de las causas por las que no se ha desarrollado suficientemente en Bolivia el uso del litigio estratégico para reivindicar derechos humanos por considerarse un mecanismo poco efectivo.

71 Sauma, Gabriela, Entrevista personal, 15 de marzo de 2018.

72 Artículos 13 y 256 CPE, El artículo 13.IV establece de manera expresa que: "los tratados y convenios internacionales ratificados por la Asamblea Legislativa Plurinacional, que reconocen los derechos humanos, prevalecen en el orden interno. Los deberes y derechos humanos contemplados en la Constitución deben interpretarse de acuerdo con los tratados internacionales de derechos humanos ratificados por Bolivia".

73 Sauma, Gabriela, Entrevista personal, 15 de marzo de 2018. 
No obstante, cuando una sentencia no es ejecutadas, son varias las medidas que puede tomar el tribunal para lograr su cumplimiento, como nos relata Gabriela Sauma:

Se emite un auto constitucional exhortando, exigiendo el cumplimiento de la sentencia, y para eso dispone de multas progresivas que puede ir aplicando a los demandados o a las personas que están incumpliendo y además puede remitir antecedentes al ministerio público, porque hay un delito que se llama desobediencia a las resoluciones pronunciadas en acciones de defensa. ${ }^{74}$

Aun así, existirían muchas sentencias que todavía no han sido ejecutadas.

\section{La definición del derecho a la vivienda a través de la jurisprudencia del Tribunal Constitucional Plurinacional}

En el ámbito concreto del derecho a la vivienda, son varias las sentencias del TCP que deben ser analizadas, en las que se determina su contenido. Lo primero que debe destacarse es que, en el desarrollo jurisprudencial de sentencias relacionadas con el derecho a la vivienda, el TCP ha tenido en cuenta los posicionamientos más progresistas de organismos internacionales. En la sentencia 0426/2012 el tribunal, siguiendo los postulados de la ONUHábitat, ha exhortado a los Estados a garantizar el derecho a la vivienda que "no es una opción política que los Estados puedan seguir o no seguir. Su reconocimiento implica una obligación jurídica para los Estados". Por este motivo la inclusión del derecho a la vivienda en la Constitución de 2009 implica la obligación de respetar, proteger y garantizar este derecho. La misma sentencia tomó también en cuenta la Declaración de Vancouver, adoptada por la Conferencia de las Naciones Unidas sobre los Asentamientos Humanos de 1976, en la que se afirma que se debe empezar "por ayudar a las capas más desfavorecidas de la población instituyendo programas que alienten la iniciativa personal y la acción colectiva”. Pero también las declaraciones de Miloon Kothari, relator especial de las Naciones Unidas sobre el Derecho a la Vivienda han sido tomadas en cuenta en la jurisprudencia del TCP: "el derecho humano a una vivienda adecuada es el derecho de

\footnotetext{
74 Idem.
} 
todo hombre, mujer, joven y niño a tener un hogar y una comunidad segura en el que puedan vivir en paz y dignidad". 75

La mencionada sentencia 0426/2012 nos muestra el interés por definir el derecho a la vivienda con base en lo establecido por distintos actores internacionales especializados en esta materia. Pero también se tomaron en consideración los instrumentos internacionales, tratados y declaraciones que, a nivel universal y regional, se han establecido en materia de vivienda. ${ }^{76}$

En la sentencia 0897/2013, relacionada con la construcción de viviendas destinadas a efectivos policiales que analizaremos más adelante, el tribunal ha interpretado, dada su "naturaleza profundamente humana", de forma amplia el alcance del derecho a la vivienda que constituiría:

1) La protección legal contra actos injustificados de desalojo.

2) Acceso a servicios de agua potable, sanitarios, electricidad y gas domiciliario, extensible a los materiales, equipamiento e infraestructura necesaria.

3) El costo accesible, incluso mediante subsidios para vivienda, y protección contra arrendatarios que se excedan.

4) La habitabilidad, incluida la protección contra el frío, la humedad, el calor, la lluvia, el viento y las enfermedades.

5) El acceso fácil para los grupos desfavorecidos, incluidas las personas ancianas, los niños, las personas con discapacidades físicas y las víctimas de catástrofes naturales.

\footnotetext{
75 Khotari, M., Informe del Relator Especial presentado en la 57a sesión de la Comisión de Derechos, Naciones Unidas, 2001.

76 La sentencia 0426/2016 cita expresamente los siguientes instrumentos internacionales: "Por su parte, el artículo 11 del Pacto Internacional de Derechos Económicos, Sociales y Culturales, reconoce "el derecho de toda persona a un nivel de vida adecuado para sí y su familia incluso $[(. .$.$) 'vivienda adecuada y a una mejora continua de las condiciones de existencia. Los$ Estados Parte tomarán medidas apropiadas para asegurar la efectividad de este derecho]”. De igual modo se encuentra reconocido en los artículos 25 inciso 1) de la Declaración Universal de Derechos Humanos (DUDH); 11.2 y 3 de la Convención Americana sobre Derechos Humanos de San José de Costa Rica; 5.e de la Convención Internacional sobre la Eliminación de Todas las Formas de Discriminación Racial; 14.h de la Convención sobre la Eliminación de Todas las Formas de Discriminación contra la mujer; 27 de la Convención sobre los Derechos del Niño; 43 de la Convención Internacional sobre la Protección de Todos los Trabajadores Migratorios y de sus Familiares; Convención sobre el Estatuto de los Refugiados que Exige a los Estados contratantes que en Materia de Vivienda Entreguen a los Refugiados el Trato más Favorable Posible; Recomendación 115, principio 2 de la Organización Internacional del Trabajo (OIT) respecto a la Vivienda de los Trabajadores de 1961".
} 
6. Estar alejado de fuentes de contaminación cercanos a los servicios básicos (P. 25).

Las implicaciones de este caso son importantes, sobre todo a la luz de la mencionada sentencia 2233/2013, lo que implica tomar estos estándares como referencia para la interpretación del derecho a la vivienda en otras ocasiones. Destaca el mandato que el TCP le da al Estado de garantizar el costo accesible a la vivienda y el acceso a la misma a los grupos vulnerables. Igualmente es importante señalar que esta sentencia relaciona el derecho a la vivienda con otros derechos como el agua, el alcantarillado y los servicios básicos, pero también con un ambiente saludable, interrelacionándose la vivienda con el hábitat.

El tribunal, en las sentencias 1329/2014 y 0348/2012, ha relacionado el derecho a la vivienda con otros derechos:

Un derecho fundamental de tercera generación emergente de los derechos económicos, sociales y culturales persigue la satisfacción de las necesidades que tienen las personas, puede entenderse como derivado de los derechos a la vida y a la dignidad, porque se trata de un lugar digno para vivir, y no simplemente de un techo para estar o para dormir; sino que es una condición esencial para la supervivencia y para llevar una vida segura, digna, autónoma e independiente; es un presupuesto básico para la concreción de otros derechos fundamentales, entre ellos, la vida, la salud, el agua potable, servicios básicos, trabajo, etcetera de modo tal, que cuando se suprime su ejercicio, implícitamente, también se amenazan a los otros derechos. No obstante, esa estrecha vinculación, no debe perderse de vista que, a partir de su incorporación en la Constitución Política del Estado como derecho autónomo, es directamente justiciable, como los demás derechos fundamentales; y, por lo tanto, es posible exigir su protección de manera franca. ${ }^{77}$

Comprobamos que para el TCP la vivienda se encuentra íntimamente vinculada con la vida, la salud, el agua potable o el trabajo, y al mismo tiempo se reconoce expresamente su justiciabilidad. Sin embargo, el tribunal también definió a la vivienda como un derecho fundamental de tercera generación, clasificación ya superada doctrinalmente pues de manera implícita refiere a la diferencia entre los distintos derechos humanos, lo que iría en contra de su indivisibilidad

77 Sentencia Constitucional Plurinacional 1329/2014; disponible en bttp://wmw.revistaboli vianadederecho.org/index.php/item/2058-scp-1329-2014-aac-30-06. 
e interdependencia. Aun así, consideramos como muy positiva la reafirmación jurisprudencial de la justiciabilidad del derecho a la vivienda por parte del TCP. Con base a este tipo de sentencias y en aras de la protección del derecho a la vivienda, los magistrados del TCP podrían realizar exhortos a las instituciones del Estado para que desarrollen políticas públicas; aunque estos exhortos, como nos relató Gabriela Sauma, se han producido en muy pocas ocasiones. ${ }^{78}$

\section{La obligatoriedad del cumplimiento de sus obligaciones por parte del Estado}

Una de las sentencias más importantes, en materia de protección de la vivienda, es el caso Consejo Nacional de Vivienda Policial (Covipol) 0897/2013, por el que a 206 policías se les había asignado una serie de soluciones habitacionales que estaban en proceso de ser construidas. El proyecto se detuvo por motivo de actos de corrupción de ciertos directivos de la Covipol; en consecuencia, por motivos completamente ajenos a los beneficiarios, su derecho a la vivienda se vio vulnerado, pues dada su precaria situación económica no contaban con viviendas adecuadas para sus familias. El TCP determinó entonces que "la "la inacción de las autoridades demandadas y del Covipol ha vulnerado flagrantemente el derecho a una vivienda digna de más de doscientas familias que conforman la parte accionante, debido a que la suspensión de la obra de ninguna manera es responsabilidad de los accionantes". 80

El TCP obligó en su sentencia a que las autoridades responsables terminaran las viviendas inconclusas para los miembros policiales cuyo derecho a la vivienda se había violado. La sentencia, en su motivación, llevó a cabo un extenso recorrido por el derecho internacional cuyo cumplimiento es obligatorio para Bolivia de acuerdo con el control de convencionalidad. El tribunal en esta sentencia vuelve a reafirmar, como en la sentencia 0426/2012, que "el derecho a la vivienda no es una opción política que los Estados puedan seguir o no seguir. Su reconocimiento implica una obligación jurídica para los Estados. La sentencia reafirma que los Estados tienen una serie de obligaciones cuyo cumplimiento es obligatorio e inexcusable, como en el caso de la construcción de las viviendas para los policías que habían cumplido con sus aportes para la construcción de una vivienda de protección social.

\footnotetext{
78 Entrevista personal, 15 de marzo de 2018.

79 Caso Covipol..., cit.

80 Idem.
} 
Esta es una importante sentencia, porque el tribunal, según Gabriela Sauma, habría reconducido la solicitud inicial de los demandantes, una acción de cumplimiento a una acción de amparo constitucional: una acción procesal, por parte del TCP, que constituye un elevado activismo judicial orientado a la garantía del derecho a la vivienda. ${ }^{81}$

\section{La relación entre el derecho al hábitaty los derechos indigenas}

El caso 0572/2014 se refiere a la demanda de la comunidad indígena Takana El Turi Manupare II, que fue objeto de amenazas y amedrentamientos con armas de fuego por quien era el concesionario de las tierras en las que se asentaba la comunidad, a raíz de un conflicto por la explotación de las castañas que existen en la zona.

En la sentencia, el tribunal interpretó en primer lugar lo que entiende por hábitat al considerar que incluye: "factores económicos, sociales y culturales que faciliten o limiten el acceso a los bienes y servicios a una sociedad". Para posteriormente relacionarlo con una serie de derechos de las naciones y pueblos indígenas originarios campesinos contemplados en el artículo 30 de la $\mathrm{CPE}$ como la libre determinación y territorialidad, junto al derecho a la titulación colectiva de tierras y territorios, y, finalmente, a "vivir en un ambiente sano, con manejo y aprovechamiento adecuado de los ecosistemas".

Tras la argumentación de los derechos considerados, el TCP concedió la tutela de la acción popular, — presentada por la comunidad Takana El Turi Manupare II - al considerar lesionado su derecho al hábitat y al domicilio, "que comprenden su territorio y el uso y aprovechamiento de los recursos naturales, que representan la base esencial de su existencia, al privarles del medio para mantener a su familia y su comunidad, vulnerando derechos conexos como la dignidad y existir libremente".

La importancia de la presente sentencia radica en que presta gran atención al desarrollo del derecho al hábitat. Por un lado, se relaciona el hábitat con el derecho al aprovechamiento de los recursos naturales, vinculándose con otros derechos como la tierra y territorio. Pero, por otro, el TCP a través del hábitat deriva en la protección del "espacio ancestral donde se desarrolla la vida social, económica, cultural, jurídica y espiritual de la comunidad, y donde, precisamente se aprovechan y se usan sosteniblemente los recursos naturales".

\footnotetext{
81 Entrevista personal, 15 de marzo de 2018.
} 
Para la letrada Gabriela Sauma, este planteamiento de la sentencia constituye un aporte original al sentar un precedente en cuanto a la presunción de ancestralidad de las tierras que ocupan las comunidades indígenas. ${ }^{82}$ Este nuevo principio de la presunción de ancestralidad no está expresamente contemplado en la Constitución, aunque podríamos interpretar que sí se encuentra en el espíritu del texto constitucional que hace referencia al término ancestral hasta en seis ocasiones, y considera en el artículo 13.II que "los derechos que proclama esta Constitución no serán entendidos como negación de otros derechos no enunciados".

Para reforzar su argumentación en defensa de los territorios ancestrales que ocupa la comunidad Takana, el TCP apoyó su argumentación en convenciones internacionales como el artículo 15 del Convenio 169 de la OIT, que determina que los pueblos indígenas tienen derecho a participar en la utilización, administración y conservación de los recursos naturales; el artículo 14 del mismo Convenio, por el que se "deberán instituir procedimientos adecuados en el marco del sistema jurídico nacional para solucionar las reivindicaciones de tierras formuladas por los pueblos interesados"; o el artículo 26 de la Declaración de las Naciones Unidas sobre los Derechos de los Pueblos Indígenas, que establece el deber de los Estados de asegurar el reconocimiento y protección no sólo de las tierras y territorios, sino también de los recursos naturales.

Comprobamos que el TCP aplicó un control de convencionalidad amplio para fundamentar sus sentencias, al tomar no solamente en consideración no sólo hard law (con carácter vinculante) internacional como el Convenio 169 de la OIT, sino también soft law (sin carácter vinculante) como la Declaración de las Naciones Unidas sobre los Derechos de los Pueblos Indígenas. Por último, como parte del control de convencionalidad amplio, el TCP también menciona las sentencias de la Corte Interamericana en las que se tuteló derechos de comunidades indígenas. ${ }^{83} \mathrm{Al}$ tomar en consideración la jurisprudencia de la Corte Interamericana de Derechos Humanos, Bolivia también

82 Idem.

83 Como la sentencia de la comunidad Mayagna (Sumo) AwasTingni contra Nicaragua, de 31 de agosto de 2001, por el que la Corte Interamericana le concedió a la comunidad la titularidad de las tierras que habitaban; el Caso del Pueblo Saramaka contra Surinam, sentencia de 28 de noviembre de 2007 , en que se relaciona el derecho a usar y gozar del territorio con los recursos naturales que se encuentran dentro del territorio; el caso Yakye Axa contra Paraguay, en el que la Corte Interamericana de Derechos Humanos sostuvo que los pueblos indígenas que hubieren perdido sus tierras por causas ajenas a su voluntad, no han perdido completamente sus derechos sobre sus territorios tradicionales, manteniendo su pretensión válida; y por último, el caso Sawhoyamaxa contra Paraguay, en el que la Corte Interamericana de Derechos 
estaría cumpliendo con sus obligaciones como Estado comprometido con esta instancia internacional. ${ }^{84}$

\section{Las vías de hecho como violación del derecho a la vivienda y el hábitat}

El caso más frecuente de protección del derecho a la vivienda y al hábitat, por parte del TCP, se ha dado en relación con las llamadas vías de hecho y desapoderamiento. Las vías de hecho tienen lugar cuando el propietario de un inmueble, para conseguir el desalojo de quien disfruta su tenencia, lleva a cabo por la fuerza y de manera ilegal una serie de acciones que pueden ir desde el corte de servicios, agua, luz, hasta el desalojo forzoso.

El desapoderamiento de una vivienda, por su parte, se relaciona con la propiedad de la vivienda y el desalojo por un procedimiento civil de las personas que se encuentran habitándola. Según Gabriela Sauma, "en esos casos el tribunal constitucional ha dado una tutela provisional, porque eran procesos que todavía no tenían sentencia con calidad de cosa juzgada, y sentencia que estuviera ejecutoriada". ${ }^{85} \mathrm{El}$ mandamiento del desapoderamiento no se dará hasta la conclusión del proceso en todas sus fases.

En la sentencia 0998/2012, el tribunal definió por vías de hecho:

$\mathrm{El}$ acto o los actos cometidos por particulares o funcionarios públicos, contrarios a los postulados del Estado Constitucional de Derecho por su realización al margen y en prescindencia absoluta de los mecanismos institucionales vigentes para una administración de justicia, afectando así derechos fundamentales reconocidos por el bloque de constitucionalidad, por lo que al ser actos ilegales graves que atentan contra los pilares propios del Estado Constitucional de Derecho.

Entre los muchos casos en los que se han considerado las vías de hecho, mencionaremos el 1948/2013, en el que los demandados fueron los propietarios, quienes juntamente con seis "cargadores" retiraron y echaron abruptamente a la calle todas sus pertenencias a los inquilinos del inmueble; evitando posteriormente su ingreso al mismo. El tribunal en este caso consideró que

Humanos hizo referencia al derecho a la reivindicación de los pueblos indígenas respecto a sus territorios ancestrales.

84 Rivera, J. A., "La aplicación del control de convencionalidad en Bolivia, en Herrera", W., Las acciones de defensa y el control de Convencionalidad en Bolivia, Kipus, 2017, pp.301.

85 Sauma, G., Entrevista con Fernando Casado de 5 de marzo de 2018. 
las personas no pueden ser desalojadas y los bienes sacados a la calle de forma desmedida y arbitraria. En consecuencia, concedió la tutela del derecho a la vivienda de los demandantes y ordenó la restitución del derecho habitacional del accionante en el bien inmueble. Hay que destacar que históricamente la legislación boliviana ha sido muy protectora de los inquilinos para evitar abusos de los propietarios. ${ }^{86}$

En otro caso relacionado con las vías de hecho y la vivienda, el 1782/2012, una mujer que vivía de alquiler en un ambiente, en una ocasión en que salió, a su retorno encontró su cuarto con dos candados, uno que puso ella y otro el propietario, quien le manifestó a la inquilina que mientras no cancelara el alquiler no le dejaría entrar a su casa, quedándose en la calle con sus dos hijos de uno y seis años. A consecuencia de los actos del propietario, los "enseres" como ropa, alimento y útiles escolares de la inquilina y sus hijos se quedaron en el cuarto.

El TCP, en este caso, relacionó con muy buen criterio las vías de hecho con la violación de otros derechos, además de la vivienda: "En ningún caso puede tomar acción por propia mano cerrando los ambientes que tenga arrendados o cortar los suministros de los servicios públicos, pues de hacerlo estaría lesionando derechos fundamentales como son los derechos al trabajo, a la dignidad, a la salud u otros".

En vista de las condiciones concretas de los demandantes, el TCP también hizo referencia a la doctrina, y a autores como Néstor Pedro Sagues, para sentar en la sentencia, "que siempre debe buscarse el entendimiento que más optimice un derecho constitucional, basándose para ello en los principios de interpretación de los derechos como el pro homine, interpretación progresiva, favor libertatis y favor debilis".

Estos principios se van a aplicar de manera prioritaria y preferencial a los grupos más débiles y vulnerables. Para el tribunal es muy preocupante la situación de indefensión en la que estarían los menores, privados de un techo, tras la decisión arbitraria del propietario del cuarto. Por ello también se hizo eco, el tribunal, de la importancia de la discriminación positiva, para "equilibrar la balanza y dar oportunidades a los grupos menos favorecidos para que puedan estar en igualdad de condiciones".

Por todos estos motivos, el tribunal consideró que el propietario debería haber acudido a la vía judicial ordinaria, y "no hacerse la justicia por sí mismo", como prohíbe el Código Civil boliviano, por lo que se habría violado el derecho a la vivienda que aparece en "la Constitución Política del Estado,

86 Vargas, M., Entrevista con Fernando Casado de 12 de Marzo de 2018. 
la Declaración Universal de los Derechos Humanos, y demás normas convencionales asumidas por nuestro Estado". Comprobamos además que en la fundamentación jurídica de la sentencia, el TCP vuelve a hacer uso del control de convencionalidad.

En el caso 0434/2015-S2, el inquilino de un inmueble demandó a su propietaria, después de que ésta tomara la justicia por su propia mano y efectuara una serie de medidas de hecho y actos violentos para desalojarle por incurrir en el impago del canon de arrendamiento, y al mismo tiempo de facturas por los meses de ocupación del inmueble.

Entre los actos, la dueña de la propiedad procedió a cambiar la cerradura de la puerta principal del inmueble y cortó los servicios de agua y la luz. Pero también procedió a amedrentar al inquilino mediante el uso de terceros para forzar su desalojo e incluso dejó a un perro propiedad del inquilino dentro del inmueble tras el cambio de la cerradura.

El tribunal consideró que las medidas adoptadas por vías de hecho violaban el derecho al hábitat del inquilino y estableció que

...el Estado está basado en el respeto e igualdad entre todos los habitantes de esta tierra, para una convivencia colectiva con acceso al agua, trabajo, educación, salud y vivienda para todos; es decir que, los servicios básicos como responsabilidad del Estado en todos los niveles de gobierno de manera directa o mediante contratos con empresas privadas como prevé el parágrafo II del artículo 20 de la citada norma constitucional, no deben ser restringidos por motivos o causas más allá de las previstas por las normas o procedimientos para tal efecto.

De esta forma el tribunal dejó sentada la jurisprudencia que impide a cualquier particular disponer de los servicios que son responsabilidad del Estado y a seguir procedimientos de desalojo que no sean los estrictamente contemplados en la ley. Nos parece igualmente importante que la argumentación del tribunal se haya producido con base al derecho al hábitat y no en relación con la propiedad privada, el derecho normalmente alegado para este tipo de casos. No obstante, cabe destacar que la jurisprudencia del tribunal en materia de vías de hecho es incluso anterior a la conformación del TCP, y es una jurisprudencia muy consolidada en Bolivia. ${ }^{87}$

87 Otras sentencias que pueden consultarse del Tribunal Constitucional anterior sobre las vías de hecho son: SSCC 0238/2000-R, 0806/2000-R,0835/2000-R, 0406/2001-R, 0607/2001R, 1286/2001-R, 1371/2001-R, 0189/2002-R, 0309/2002-R,0543/2002-R y 1549/2002-R. 


\section{Elprincipio de verdad material}

El caso 0426/2012 tiene relación con la violación a los derechos a la vivienda y propiedad privada, por el cual un grupo de personas a quienes se benefició para la compra de terreno y construcción habitacional como parte del Programa de Vivienda Social y Solidaria del Viceministerio de Vivienda y Urbanismo fueron invadidos en sus predios de forma ilegal y violenta. Los invasores ocuparon las casas concluidas y en construcción, llevándose materiales de obra, colocando banderas bolivianas, wiphalas y emblemas del MAS, autodenominándose como "Invasión Álvaro García Linera”. Pese a la mediación de distintas instituciones, los invasores nunca abandonaron los terrenos y trataron de consolidar la ocupación del lugar.

En un primer momento, el tribunal de garantías permitió el avasallamiento al denegar la acción tutelar de los derechos de los demandantes. Situación que se produjo incluso si "los demandados no negaron en ningún momento el avasallamiento ilegal y arbitrario que hicieron, sino más al contrario, mediante cartas consintieron y aceptaron su conducta".

Dada la importancia manifiesta del "acceso a la justicia constitucional de los justiciables”, el TCP consideró que debía aplicarse el llamado principio de verdad material, por mandato del cual "se debe anteponer la verdad de los hechos ante cualquier situación", especialmente al haber un reconocimiento del avasallamiento por parte de los demandados. Por lo tanto, frente a la posible duda de si la demanda se interpuso en los plazos adecuados u otras consideraciones formales o materiales, el tribunal consideró que debía imperar la justicia y los derechos legítimos de los beneficiarios de la PVSS cuyas viviendas fueron ocupadas ilegalmente.

El principio de verdad material aplicado en la defensa del derecho a la vivienda cobra un mayor sentido en tanto que el avasallamiento ilegal y arbitrario de las viviendas y propiedades de los beneficiarios de la PVS constituyó un atropello de derechos con base en medidas de hecho, que como vimos, la jurisprudencia boliviana de manera uniforme y categórica ha rechazado. Como consecuencia de la aplicación de las vías de hecho, por parte de los invasores, el TCP determinó que "El derecho a la vivienda es un derecho humano fundamental y que en este caso se advierte que los accionantes se encuentran en una situación de desprotección frente a la ocupación realizada por los demandados, no pudiéndose materializar el programa social de vivienda del que forman parte".

En consecuencia, el tribunal consideró que el tribunal de garantías no aplicó de manera adecuada la jurisprudencia en el presente caso, por lo que 
revocó la sentencia dictada para poder otorgar la tutela solicitada a los demandantes. A los demandados, por su parte, se les otorgó veinte días para desocupar las viviendas y propiedades, encargando al tribunal de garantías "el cumplimiento de la presente determinación, sea con ayuda de la fuerza pública en caso de ser necesario".

\section{Los desalojos de la vivienda}

Un tema muy controvertido es cómo se deben solucionar los desapoderamientos y desalojos de una vivienda, teniendo en cuenta que el afectado por esta medida queda excluido del disfrute del derecho. Por este motivo, los casos en que se produzcan desalojos, éstos deben ser en todo momento acordes con la ley y solamente en aquellos casos que estén perfectamente justificados, tal y como lo determinan los Comentarios Generales del Comité DESC No. 7 sobre el derecho a una vivienda adecuada.

No obstante, hay que tener en cuenta que, pese a la justificación para llevar a cabo el desalojo y proceder a la salvaguardia del derecho a la propiedad del dueño del inmueble, la persona que sufra el desalojo quedará privada de vivienda y por tanto de un derecho fundamental, a no ser que se establezcan mecanismos alternativos de protección, como los alojamientos o refugios temporales.

Dado que el derecho a la vivienda ha sido considerado por el TCP como fundamental-fundamental, y por su relación con otros derechos que podrían verse afectados en la sentencia 2164/2013, determinó que "cuando existan mandamientos de desapoderamiento, pretendiendo desalojar a una o varias personas de un bien inmueble, es posible otorgar una tutela de carácter "provisional", siempre y cuando exista pendiente algún recurso o proceso que dilucidará la legalidad o correspondencia o no de la referida medida".

El tribunal con esta decisión, trató de impedir que las personas afectadas por una medida de desapoderamiento de un inmueble que ocupaban durante más de 18 años quedaran desprotegidas mientras exista "algún mecanismo que podría determinar que no corresponde el desalojo”, cuando además los afectados alegaban que nunca habían sido parte del proceso ni tenido la oportunidad de ejercer su respectiva defensa. Es por ello por lo que se aplicó la tutela "provisional" por parte del tribunal "que impida cualquier lesión a otro derecho" que pueda resultar como consecuencia de la restricción de la vivienda. Por una parte, consideramos loable el esfuerzo del tribunal por proteger los derechos fundamentales, aunque sea de forma provisional, pero por otra, notamos que el derecho a la vivienda cobra sentido cuando está en relación 
con otros derechos, pero no de forma autónoma, por lo que puede ser restringido en pro de otros derechos, como las reivindicaciones - legítimasde los propietarios de un inmueble. La consecuencia final será la conculcación del derecho a la vivienda.

El propio TCP, en la misma sentencia 2164/2013, estableció que los derechos en conflicto para cada caso concreto deben ser ponderados. Las reglas para seguir serían: "1) Definir el grado de la no satisfacción o de afectación de uno de los derechos; 2) definir la importancia de la satisfacción del derecho que se juega en sentido contrario; y 3) definir si la importancia de la satisfacción del derecho contrario justifica la afectación o no satisfacción del otro".

En el presente caso, lo que determinó sin lugar a duda el tribunal fue que, en el caso de sacrificar el derecho a la vivienda de los accionantes, "se estaría vulnerando no sólo ese derecho, sino también el de la dignidad humana de los mismos y de su entorno familiar". Este sería el bien jurídico más importante que estaría en juego sobre el resto en conflicto, y tendría como consecuencia dejar "en la calle, y en total estado de desprotección a una familia entera". En consecuencia, el TCP concluyó que "la satisfacción del derecho de acceso a la justicia del tercero interesado no justifica la afectación del derecho a la vivienda de los accionantes".

La tutela provisional del derecho a la vivienda se llevará a cabo de manera provisional, hasta que el proceso de usucapión se concluya una vez dictada sentencia, de esta forma el tribunal persigue "un equilibrio práctico entre las necesidades de los titulares de ambos derechos en colisión”. En el presente caso el tribunal también quiso aclarar que la protección otorgada mientras dure el proceso de usucapión se otorgó a los accionantes porque pudieron probar que vivieron durante dieciocho años en la propiedad en disputa.

Una vez más, lo que el TCP quiere dejar claro es que no se establecerán reglas generales para determinar la protección de una de las partes, es decir, que no necesariamente va a prevalecer siempre el derecho a la vivienda. Por un lado, el tribunal pareciera que quiere evitar que se produzcan abusos por alguna de las partes, pero por otro, si cada caso concreto va a ser analizado, la subjetividad del juez le otorga un elevado nivel de discrecionalidad, y no siempre se ponderará en favor del derecho a la vivienda necesariamente. Existe el riesgo de que no se produzca una ponderación justa si no se establecen reglas fijas para situaciones más o menos generales o para ciertos derechos en disputa, nos parece que mientras exista un proceso en marcha, sin sentencia firme, el derecho a la vivienda indefectiblemente debe prevalecer sobre los derechos procesales o la propiedad privada, como ocurre en el presente caso. 
De hecho, el TCP dejó constancia que para futuros casos análogos de desapoderamiento contra los ocupantes de una propiedad:

Necesariamente los accionantes deberán adjuntar prueba idónea que certifique su posesión en el inmueble que pretende ser desapoderado, y que permita tener cierto grado de certeza a los jueces que dentro de una demanda de usucapión se podrá probar su derecho posesorio, como en este caso, fueron las certificaciones de la junta vecinal y facturas de agua y luz.

El tribunal trató de evitar que la iniciación de un proceso como el de usucapión pueda paralizar la ejecución de otro proceso en curso de desapoderamiento. Probar los derechos posesorios sobre un inmueble que se habite es importante, pero en estas diatribas el tribunal pudiera estar perdiendo de vista la fundamental importancia que siempre y en todas las circunstancias va a tener la protección del derecho a la vivienda.

\section{CONCLUSIONES}

La constitución de 2009 ha insertado a Bolivia en el grupo de los países que forman parte del nuevo constitucionalismo latinoamericano, abriendo brechas en el paradigma liberal de los derechos humanos al considerar todos los derechos humanos sin excepción como justiciables. Es más, la sentencia 1696/2014 ha llegado a considerar a todos los derechos constitucionales como subjetivos, una denominación que históricamente había sido exclusiva de los derechos civiles y políticos.

Nuestro trabajo se ha centrado en constatar si la ruptura normativa se ha traslado a la tutela del derecho a la vivienda, un derecho reconocido como fundamental-fundamental, pero que pese a su importancia y relación con otros derechos ha sido históricamente marginado por la tutela judicial.

Hemos podido verificar que desde la entrada en vigor de la Constitución y el TCP han sido muchas las sentencias dictadas protegiendo el derecho a la vivienda, principalmente prohibiendo medidas de hecho, avasallamientos y desapoderamientos arbitrarios e ilegales, que han puesto límites a la propiedad privada en pro del derecho a la vivienda y al hábitat. Al mismo tiempo, el TCP, ha mostrado gran sensibilidad por los grupos vulnerables y ha aplicado medidas de discriminación positiva hacia grupos vulnerables y personas que podrían haber quedado en indefensión ante quienes se han tomado la justicia por su propia mano. De esta forma se han evitado desalojos y ocupaciones ilegales. 
Igualmente celebramos el reciente control de convencionalidad, del que ha hecho uso el TCP en la tutela del derecho a la vivienda para fundamentar sus sentencias, llegando a considerar los magistrados como propias las decisiones más progresistas de la Corte Interamericana.

El TCP ha llegado a regular el hábitat en relación con los pueblos indígenas y a considerar el principio de ancestralidad en el caso de la comunidad Takana, lo que constituye un activismo judicial poco común y que coloca a los magistrados responsables de esta interpretación de los derechos colectivos y la acción popular a la altura del mandato constitucional.

Pese a las críticas vertidas sobre el TCP, por estar subordinado a los intereses y agenda del poder político, lo que enturbiaría el desempeño general del tribunal, y que afectaría principalmente a la tutela de ciertos derechos civiles y políticos, no se pueden negar los avances en materia de derechos sociales como el derecho a la vivienda. Gracias a sentencias como la 2233/2013, que obligan a la aplicación de los estándares más altos, se espera que en el futuro se sigan produciendo avances en materia de protección de derechos humanos. Ahora bien, la consideración de la revisión de cada caso particular y la ponderación de los derechos en conflicto, en casos como los de desalojo, como se establece en la sentencia 2164/2013, permiten gran discrecionalidad a los jueces e interpretaciones conservadoras que podría afectar la protección del derecho a la vivienda.

En consecuencia, mucho queda por tanto aún por hacer, y la apuesta es que se sigan profundizando las sentencias que redunden en beneficio de la garantía del derecho a la vivienda y hábitat, transgrediéndose las fronteras marcadas por la visión liberal de los derechos humanos.

\section{BIBLIOGRAFÍA}

ABI, Gobierno promete construir 100 mil viviendas hasta 2015 y eliminar déficit habitacional en Bolivia, Eju!, 8 de octubre de 2011; disponible en bttps:/ / bit.ly/3upyBdA.

ApazA, A., Entrevista con Fernando Casado, 11 de marzo de 2018.

CANEDO A., Una aproximación a indicadores DESC para Bolivia, Capítulo Boliviano de Derechos Humanos, Democracia y Desarrollo, 2009; disponible en https:/ / bit.ly/3dzKhDH.

Caso Adolfo Colque Maraza y otros miembros de la Comunidad de Chillcani, 1696, Tribunal Constitucional Plurinacional, 4 de noviembre de 2013. 
Caso Carmen Lixi Sanjinés Tuno, 1782, Tribunal Constitucional Plurinacional, 1 de octubre de 2012.

Caso Comunidad Takana, 0472, Tribunal Constitucional Plurinacional 10 de marzo de 2014.

Caso Covipol, 0897/2013, Tribunal Constitucional Plurinacional, 20 de junio de 2013.

Caso Milgia Gabriel Flores, 0450/2012, Tribunal Constitucional Plurinacional, 29 de junio de 2012.

Caso Servicio Departamental de Salud (Sedes), 0121/2012, Tribunal Constitucional Plurinacional, 2 de mayo de 2012.

Caso Wagner Baptista Millares, 1948, Tribunal Constitucional Plurinacional, 4 de noviembre de 2013.

Caso Waldy Chávez Menacho, 0998, Tribunal Constitucional Plurinacional, 5 de septiembre de 2012.

Caso Willan Enrique Ávila Flores y otros, 0426, Tribunal Constitucional Plurinacional, 2 de Junio de 2012.

CONOCE los resultados del Tribunal Constitucional, El Deber, 3 de diciembre de 2017; disponible en: bttps:/ / bit.ly/3dDNGBf.

Durán, W., Principios, derechos y garantías constitucionales, El País, 2005.

Estado Plurinacional De Bolivia (ed.), Construyendo comunidades urbanas para vivir bien en el siglo XXI, Conferencia Mundial Habitat III, 2016, disponible en https:// bit.ly/2Q0ohtD.

Ferrajoli, L., Derechos y garantías, La ley del más débil, Madrid, Trotta, 1999.

FORO Permanente de la Vivienda, Política estatal de vivienda, Bolivia, Imprenta Punto de Encuentro, 2009.

Geovanni Miguez vs. Matilde Vargas, 0434 S-2, Tribunal Constitucional Plurinacional, 29 de abril de 2015.

GÓMEZ, B., "Beneficiadas más de cien familias con viviendas sociales en Bolivia", "Radio Habana Cuba", 4 de mayo de 2017, disponible en https:// bit.ly/3fOailk.

INSTITUTO NACIONAL DE EsTADísTiCA (ed.), Estadisticas en construcción de vivienda. Instituto Nacional de Estadística, 2017.

JiMÉNEZ, S., "Por el reconocimiento y justiciabilidad del derecho humano a la vivienda en Bolivia". INVI 23 (62), 2008, disponible en https:// bit. ly/39Lg2Z8. 
JIMÉNEZ, S., La cuestión socio habitacional en Bolivia. Actualización de datos censales en base a los resultados oficiales publicados por el INE en agosto del 2014, INE, 2014.

KHOTARI, M., Informe del Relator Especial presentado en la 57 a. sesión de la Comisión de Derechos, Naciones Unidas, 2001.

LECOÑA, J. Q., Acciones de defensa y catálogo de derechos bumanos en la nueva constitución, Sigla Editores, 2010.

LOAYZA, M., Entrevista con Fernando Casado de 12 de marzo de 2018.

MeléndeZ, A., Entrevista con Fernando Casado de marzo de 2018.

Ministerio DE OBRAS PÚBliCAS (ed.), Construyendo comunidades urbanas para vivir bien en el siglo XXI. Informe del Estado plurinacional de Bolivia para hábitat III, 2016.

Naciones Unidas (ed.), Declaración de Vancouver sobre Asentamientos Humanos, Vancouver, Naciones Unidas, 1976.

NoguerA, A., "¿Derechos fundamentales, fundamentalísimos o, simplemente, derechos? El principio de indivisibilidad de los derechos en el viejo y el nuevo constitucionalismo, Derechos y Libertades, núm. 21, disponible en bttps:/ / bit.ly/3dHmHoJ.

NoguerA, A., Los derechos sociales en las nuevas Constituciones latinoamericanas, Tirant lo Blanch, 2010.

PINTO, Y. C., La justiciabilidad y efectividad de los derechos económicos, sociales y culturales en el Estado boliviano, al amparo de la Constitucion Política del Estado y los tratados de derechos humanos ratificados, Red de Profesionales Abogados en Derechos Humanos, Capacitación y Derechos Ciudadanos, 2012.

RENASEH (ed.), Informe: Derecho Humano a la Vivienda en Bolivia, Examen Periódico Universal, 2010.

RiverA, J. A., "La aplicación del control de convencionalidad en Bolivia", en Herrera, W., Las acciones de defensa y el control de convencionalidad en Bolivia, Kipus, 2017.

SAAVEDRA, S., Entrevista con Fernando Casado de 12 de marzo de 2018.

Santiago, S., Guarayo, H., Interdialogando. Hacia la constitución plural del derecho desde la cosmovisión de la nación Yampara, Konrad Adenauer Stiftung, 2014.

Sauma, G., Entrevista con Fernando Casado de 15 de marzo de 2018.

Sotillo, A., "Desarrollo jurisprudencial de la acción popular en Bolivia", en Herrera, W., Las acciones de defensa y el control de convencionalidad en Bolivia, Kipus, 2017. 
Tribunal Constitucional De Bolivia (ed.), Derechos fundamentales y acciones de defensa, 2009.

UN-Habitat (ed.), A Safe City is a Just City, 2007.

VARGAS, A., La acción de amparo constitucional en Bolivia, en HERRERA, W. (ed.), Las acciones de defensa y el control de convencionalidad en Bolivia, Kipus, 2017.

VArGas, M., Entrevista con Fernando Casado de 12 de marzo de 2018.

VeláZQUeZ, L., Entrevista con Fernando Casado de 13 de marzo de 2018. 